\title{
6. Observations on Isolated Red Pigment Granules from Midgut Erythrophores of a Shrimp, Caridina denticulata
}

\author{
By Mitsuharu MiYawaki, Takanori Tsuruda, and Izumi YoshiokA \\ Department of Biology, Faculty of Science, \\ Kumamoto University, Kumamoto 860
}

(Communicated by Sajiro Makino, M. J. A., Jan. 13, 1986)

During previous studies (Miyawaki and Taketomi, 1984; Miyawaki and Tsuruda, 1984a, b, 1985a-c), we have frequently noticed that the red pigment can flow out of an erythrophore whose cell membrane has been ruptured. Interestingly, as seen with a light microscope, the cytoplasm leaves the erythrophore as a string or thread. This result undertook to examine, using the electron microscope, this linearly arranged red pigment and to determine how it behaves in various solutions. Studies of pigment granule movement in various kinds of chromatophores have been concerned largely with the participation of microtubules (Noël, Hubert, Couturier-Bhaud, and Chasard-Bouchaud, 1983, etc). In crustaceans, migration of the pigment is under the control of neurosecretory substances, neurohormones, from the central nervous system, the $\mathrm{X}$ organ-sinus gland complex in particular. The results presented herein were obtained from electron microscope observations on red pigment granules which had been experimentally induced to flow out through broken cell membranes in order to observe the arrangement of the granules and any accompanying microtubules or microfilaments.

Materials and methods. The shrimp were collected from Lake Edzu, Kumamoto City, and were kept in laboratory aquaria. The water temperature was about $25^{\circ} \mathrm{C}$, and there was a $12 \mathrm{~L} / 12 \mathrm{D}$ illumination with an intensity of 160 lux. They were fed a weed, Egeria densa.

Erythrophores on the surface of the midgut which was dissected out from living shrimp were used. The cell membrane of a chromatophore was pricked with a fine needle. As a result the cytoplasmic matrix containing tiny strings of pigment granules flowed out from the cells. These pigment strings were then transferred to a carbon film on the copper grids on which a little amount of Locke's solution was placed beforehand. An equal volume of $8 \%$ glutaraldehyde was added, and then material was dried and postfixed with $1 \%$ osmium tetroxide. Observations were carried out after washing the material in distilled water. A JEM $100 \mathrm{C}$ electron microscope at $80 \mathrm{KV}$ was used. In the early part of this study the pigment was prefixed with glutaraldehyde but soon became clear that no difference could be detected between the results with the dual fixation and single fixation, so in the late part of this study only osmium fixed ones were used. Furthermore, to eliminate the effect of inorganic ions, $0.32 \mathrm{M}$ solutions of sucrose, glucose and urea were used during dissection and suspension of the pigment granules instead of Locke's solution.

Results. As mentioned above, flown out cytoplasmic matrix contained thread-like red pigment which is conceivably indicating the arrangement of the pigment granules in the erythrophores. The electron micrographs revealed that 


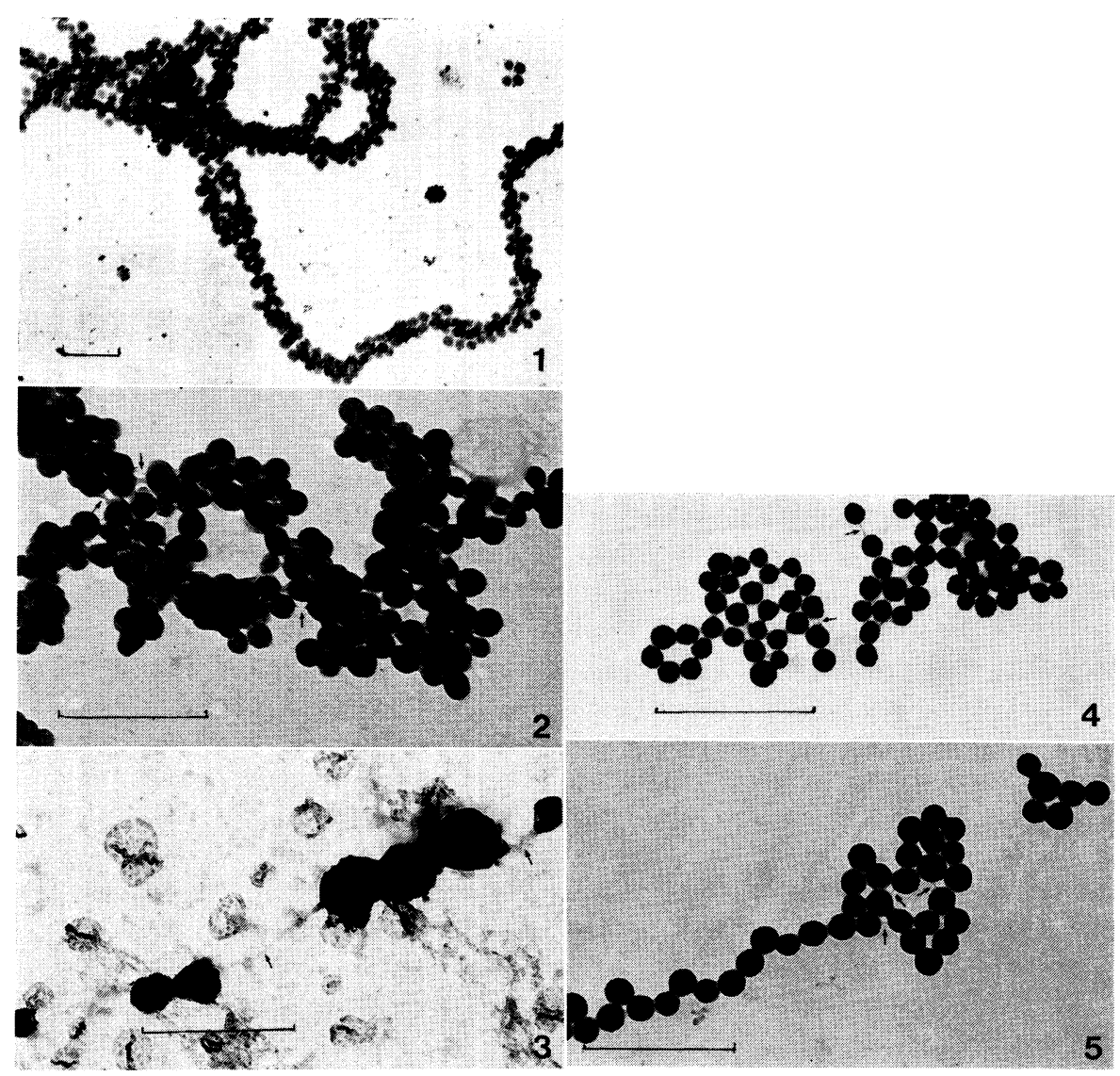

Figs. 1-5. 1: Electron micrograph of isolated pigment granules in Locke's solution. 2: The same as in Fig. 1, high magnification. 3: An electron micrograph of isolated pigment granules with some erroneous treatment. 4: Isolated pigment granules in sucrose solution. 5: Pigment granules isolated in glucose solution. Arrows in these figures indicate microfilaments connecting neighboring pigment granules. Scale bars $=0.5 \mu \mathrm{m}$.

naked pigment granules having a linear arrangement, like beads on a necklace. And the granules seem to be connected with fine cytoplasmic strands or microfilaments (Figs. 1, 2). Occasionally, fine microfilaments could be observed between neighboring pigment granules. In some cases, when the fixation might be imperfect, the pigment granules were deformed in an irregular shape (Fig. 3). These deformed granules were still connected with microfilaments. So that the microfilaments were certainly present connecting the pigment granules. Solutions of several organic, nonelectrolite compounds were used in dissection and subsequent isolation of the pigment granules did not affect their shape and size. The microfilaments connecting the pigment granules were observable more easily in these solutions than in the use of Locke's solution (Figs. 4, 5). This might be due to the presence of $\mathrm{Ca}$ ion in Locke's solution which is considered to cause the concentration ( aggregation) of the pigment granules. Coincident to this, the pigment granules isolated in Locke's solution were observed piling up compli- 
catedly, while in the solutions of organic compounds the granules scattered flatly.

Discussion. The fact that the isolated pigment granules showed a linear arrangement in Locke's solution and in solutions of the organic compounds, and that cytoplasmic strands or microfilaments were found with these isolated glanules suggests that the microfilaments are indeed present in the erythrophores on the internal organs, and connect neighboring pigment granules each other.

It has been generally perceived that the pigment granules move along the bundles of microtubules when they migrate. This conclusion has been largely obtained from observations on the melanophores of both invertebrates and vertebrates. Seemingly, either there are significant differences between the mode of translocation of the pigment granules of melanophores and erythrophores or it is due to the difference of methods of observations. In the present study, observations were carried out in the isolated condition while usual observations were made in the embedded and sectioned ones. As a matter of fact, when was observed the embedded and sectioned material, we could not notice the microfilament connecting the neighboring granules. Furthermore, most of the observations reported were for integumentary chromatophores. The chromatophores on the internal organs have not been studied exclusively, but Robison and Charlton (1973), Lambert and Fingerman (1978), and McNamara (1979, 1980, 1981, 1982) have reported on them. Lambert and Fingerman (1978) reported the occurrence of the elements of microtrabecular lattice which connects the pigment granules of melanophores of Uca pugilator. They used embedded materials with specially modified fixation. Porter and McNiven (1982) observed also microtubular lattice in the erythrophores of a fish, Holocentrus ascensionis, applying high voltage electron microscopy. The authors of these two papers certainly showed the lattice or meshwork but not the linear strands observed in the present study. The difference might be due to the difference of methods. We used isolated pigment granules of erythrophores but they used embedded materials. It seems probable that there are some relations between their observations and ours.

Acknowledgements. The writers express their cordial gratitude to Professor Milton Fingerman, Tulane University, New Orleans, Louisiana, for his critical reading of the manuscript. We are also greatly indebted to Dr. S. Makino, M. J. A., Professor Emeritus of Hokkaido University, for review of this manuscript.

\section{References}

Fingerman, M. (1985) : Amer. Zool., 25, 233-252.

Kleinholz, L. H. (1985) : The Biology of Crustacea. vol. 9 (eds. D. E. Bliss and C. H. Mantel). Acad. Press, New York.

Lambert, D. T., and Fingerman, M. (1978) : Biol. Bull., 155, 563-575.

McNamara, J. C. (1979) : J. exp. mar. Biol. Ecol., 40, 193-199.

(1980): ibid., 46, 219-229.

(1981) : Biol. Bull., 161, 270-280.

McNamara, J. C., and Sesso, A. (1982) : Cell Tissue Res., 222, 167-175.

Miyawaki, M., and Taketomi, Y. (1984): Proc. Japan Acad., 60B, 13-16.

Miyawaki, M., and Tsuruda, T. (1984a) : ibid., 60B, 241-244.

(1984b) : ibid., 60B, 349-352.

(1985a) : ibid., 61B, 16-19.

(1985b) : ibid., 61B, 113-115.

(1985c) : Cell Biol. Internl. Rep., 9, 555-559. 
Noël, P. et al. (1983) : Bull. Soc. France, 108, 223-229.

Porter, K. R., and McNiven, M. A. (1982) : Cell, 29, 23-32.

Robison, W. G., and Charlton, S. (1973) : J. Exp. Zool., 186, 279-304. 